\title{
A (RE)PRODUÇÃO DO ESPAÇO A PARTIR DO FENÔMENO TURÍSTICO: UM ESTUDO SOBRE A COMUNIDADE DE AVER-O-MAR (SIRINHAÉM - PE)
}

\author{
The space (re)production from the touristic phenomenon: the case of \\ Aver-O-Mar community (Sirinhaém-PE)
}

\author{
Itamar Dias e CORDEIRO ${ }^{1}$ \\ Cláudio CASTILHO ${ }^{2}$
}

\section{RESUMO}

Este estudo discute o papel do turismo como vetor de (re)produção do espaço litorâneo no nordeste. Como estudo de caso, tomou-se a realidade da Praia de Gamela e da comunidade de pescadores artesanais de Aver-O-Mar, situada no Litoral Sul de Pernambuco. Observou-se que o processo de turistificação do espaço começa com a criação da ideologia de que o turismo é a "vocação natural" para o aproveitamento dos espaços litorâneos. Forma-se uma imagem da praia como paraíso tropical e, em seguida, há uma espetacularização dela. Como resultado surge um espaço alienado onde: o nativo (pescador) não reconhece o lugar; o turista vive uma fantasia e onde o espaço perde sua identidade.

\section{Palavras-chave:}

Turismo; áreas litorâneas; Praia de Gamela; (re)produção do espaço; turistificação.

\section{ABSTRACT}

This study aims at discussing the role of tourism while an item of the northeastern littoral's space (re)production. The reality of Gamela's beach and the Aver-O-Mar traditional fisherman's community, located at Pernambuco's Southern Littoral, were taken as case instances. The touristification process of the space started with the tourism ideology that tourism is the "natural vocation". An image as a beach while the tropical paradises was created and as a result the local fisherman does not recognise his/her place; a fantasy is lived by tourists and the space loses its identity.

\section{Key-words:}

Tourism; Littoral areas; Gamela's Beach; Space (re)production; Touristification.

1 Turismólogo (UFPE), Gestor Ambiental (Cefet-PE), Especialista em Gestão e Políticas Ambientais (UFRPE), Mestrando em Geografia (UFPE), Bolsista CNPq. E-mail: itamar_cordeiro@yahoo.com.br

2 Professor Orientador, Docente do Programa de Mestrado em Geografia (UFPE). E-mail: jcmc@ufpe.br 


\section{INTRODUÇÃO}

O entendimento do processo de produção do espaço pode fornecer subsídios essenciais ao processo de desenvolvimento de determinado local. Neste sentido buscou-se investigar a produção de um espaço específico: o espaço turístico de litoral. O motivo dessa escolha deve-se tanto à singularidade do litoral, como ao poder que o turismo tem para reorganizar os espaços.

A grande importância atribuída à zona costeira deve-se a seu amplo espectro de oportunidade: do ponto de vista econômico, gozam de relativa raridade com relação às demais porções das terras emersas; com relação às formas de vida que nelas habitam, são áreas com enorme biodiversidade; estrategicamente, são os portões de entrada e saída para os fluxos transoceânicos e, por fim, possuem clara importância político-administrativa, uma vez que "cerca de dois terços da humanidade habitam em zonas costeiras, localizando-se à beira-mar a maior parte das metrópoles contemporâneas" (MORAES, 1999, p.18).

Historicamente considerada como um espaço coletivo de lazer, a praia incorpora, no imaginário popular contemporâneo, o ambiente ideal para a fuga da rotina maçante e exploradora dos centros urbanos. Considerando que "todos aqueles que são escravos do trabalho e que fazem parte da sociedade industrial necessitam desse consolo 'externo'” (KRIPPENDORF, 2003, p.37), a idéia da praia como local de lazer se reafirma hoje, mais do que nunca, com extremo vigor.

Essa forma de entender o litoral desencadeou um vertiginoso processo de urbanização, e sua utilização para fins turísticos é uma das formas de uso mais recorrentes. Com efeito, a influência do turismo sobre o espaço sempre foi no sentido de buscar criar um ambiente propício ao turista e não ao morador tradicional. No caso específico da Região Nordeste, Fonseca \& Costa (2004, p. 25) constataram que esses espaços tendem a ser produzidos em função exclusiva dos visitantes. Destarte, tem-se que o espaço turístico no litoral, desde sua gênese, entra em flagrante discordância com as perspectivas das populações tradicionais, nomeadamente, a de pescadores.

Dado o impacto que a produção do espaço turístico tem na vida das comunidades de pescadores e tendo em vista a importância social que o tema suscita, tratouse de analisar como se processa, de forma geral, a formação desses espaços turísticos litorâneos. Como objeto de estudo elegeu-se a Praia de Gamela, localizada na área do Centro Turístico Guadalupe (CTG), no município de Sirinhaém, litoral sul do estado de Pernambuco.

A escolha dessa área decorre do fato de que o CTG, idealizado no âmbito do Projeto Costa Dourada e viabilizado com recursos do Prodetur/NE I, inseriu novas formas que acabaram por refuncionalizar o espaço dos pescadores da Vila de Sirinhaém (Praia de Gamela). Na medida em que formas não são única e simplesmente formas, mas formas-conteúdo, houve, em Gamela, uma verdadeira refuncionalizacão do espaço. Assim, para além do simples processo de urbanização turística, este estudo buscou entender como se processa a produção de um espaço turístico no litoral do nordeste do Brasil.

\section{O ESPAÇO TURÍSTICO COMO MERCADORIA}

Tendo em vista que "a riqueza das sociedades onde rege a produção capitalista configura-se em imensa acumulação de mercadorias, e a mercadoria isoladamente considerada, é a forma elementar desta riqueza" (MARX, 2004, p. 57) e considerando que "o turismo faz parte do mundo das mercadorias que atende às novas necessidades geradas pelo capitalismo, na sociedade de consumo" (CORIOLANO, 2006, p. 23) é providencial realizar uma caracterização do que é "mercadoria" na lógica de funcionamento do fenômeno turístico.

Para Marx, mercadoria é a expressão material do trabalho humano imbuída de valor de troca, ou seja, um artefato que só existe por ocasião do dispêndio de trabalho humano que não possui valor de uso para quem o produz, mas apenas para aquele que pretende adquiri-lo ${ }^{3}$. Conseqüentemente, as mercadorias não possuem utilidade para seus fabricantes, sua existência baseia-se na perspectiva de sua aquisição por outrem.

Sob esse ângulo, virtualmente tudo pode ser considerado como mercadoria, inclusive o espaço, se utilizado comumente como estratégia para acumulação de riqueza. Considerando, como afirma Santos (2004b, p. 30), que "o espaço tornou-se a mercadoria universal por excelência", as estratégias para a mercantilização do espaço são as mais diversas e o turismo certamente "é uma das atividades capitalistas que torna os lugares mercadoria" (CORIOLANO, 2006, p. 46). Nesta mesma perspectiva, Adorno (2002, p. 106) observou que, "os fenômenos específicos do tempo livre como o turismo e o camping são acionados e organizados em função do lucro". Fica claro, pois, que o espaço possui, para o turismo, um valor.

3 "[...] quem, com seu produto, satisfaz a própria necessidade gera valor de uso, mas não mercadoria. Para criar mercadoria, é mister não só produzir valor de uso, mas produzi-lo para outros, dar origem a valor de uso social" (MARX, 2004, p. 63). 
Como valor de uso, o espaço se destina à exploração para a subsistência e é "marcado pelo respeito aos ciclos da natureza e pela sua explotação, observando-se a capacidade de recuperação das espécies de animais e plantas utilizadas" (DIEGUES; ARRUDA, 2001, p. 25). O que o fenômeno do turismo faz é transformar o espaço em mercadoria e converter seu valor de uso em valor de troca. Trata-se, portanto, de criar um espaço para atender aos anseios de pessoas dispostas a pagar para utilizá-lo. Isto se dá, geralmente, por meio da inserção de formas espaciais específicas como equipamentos de lazer, de acesso, de hospedagem e outras facilidades, comumente chamadas de infra-estruturas turísticas.

São esses fatores que norteiam as ações que irão atuar sobre o espaço, afinal, "o espaço produzido é um resultado da ação humana sobre a superfície terrestre que expressa, a cada momento, as relações sociais que Ihe deram origem" (MORAES, 2005, p. 15). Em última análise, pode-se afirmar que o fenômeno do turismo é o da extinção do valor de uso de um espaço em função do valor de troca, uma vez que, como afirma Coriolano (2006, p. 21) o turismo é "uma invenção do capitalismo".

Com base nesse pressuposto, entende-se que a compreensão sobre a produção de um espaço turístico deve ser a do espaço como mercadoria, de vez que não há registros de destinos turísticos surgidos em função da "troca de experiência" ou do "prazer em receber o visitante". Sem exceções, todos os destinos turísticos vão se originar com o único intuito de obter retornos financeiros em troca da visitação. Esta é lógica da produção do espaço turístico, que, por seu turno, não é nada mais que o reflexo da lógica de conversão do valor de uso em valor de troca.

Importante observar que, ao ser convertido em mercadoria, fica o espaço sujeito às leis de mercado, de modo que "os mesmos fatos e leis econômicas que se aplicam a qualquer indústria podem ser aplicados à empresa de turismo" (BENI, 2002). Ademais, na condição de mercadoria, o espaço turístico tende a ser interpretado como uma "coisa trivial, imediatamente compreensível. Analisando-a, vê-se que ela é algo muito estranho, cheio de sutilezas metafísicas e argúcias teológicas" (MARX, 2004, p. 92).

Longe de ser um simples receptáculo estático das ações humanas, o espaço "está em evolução permanente" (SANTOS, 1985, p. 16). Tal evolução resulta do processo dialético estabelecido entre o suporte físico e a vida que nele está contida. De forma sucinta, significa que o ser humano, ao atuar "sobre a natureza externa e modificando-a, ao mesmo tempo modifica sua própria natureza" (MARX, 2004, p. 211). Assim, consoante Santos (2004a, p. 63), entende-se que o espaço, deve ser interpretado enquanto um "conjunto indissociável, solidário e também contraditório, de sistemas de objetos e sistemas de ações não considerados isoladamente, mas como quadro único no qual a história se dá".

Adotar essa interpretação implica aceitar que os objetos condicionam a maneira como as ações ocorrem no espaço, tanto quanto as ações conduzem à criação de novos objetos ou mesmo a refuncionalização de antigos, e sendo o espaço um produto da relação dialética entre esses dois sistemas, a diferença entre os vários tipos de espaços decorre dos objetos neles existentes e das ações neles praticadas.

Portanto, os espaços são produzidos, fundamentalmente, a partir das ações humanas direcionadas a utilizar, segundo suas necessidades, a estrutura física de determinados locais. O que ocorre é que, a "necessidade" daqueles que se empenham na produção dos espaços turísticos é sua utilização para a obtenção de dinheiro oferecendo atração aos visitantes.

O espaço que servia de base física à subsistência de uma comunidade, é convertido num espaço destinado à satisfazer as necessidades de pessoas alhei$a^{4}$; eis o leitmotiv do espaço turístico. Tendo em vista que os turistas buscam o inusitado, algo que não encontram em suas áreas de origem, são as singularidades que constituem o que se chama de "atrativo turístico". A situação geográfica tem, pois, função determinante na formação dos espaços turísticos. Na Região Nordeste do Brasil, um dos espaços mais singulares é o litoral. Justamente por conta dessa singularidade, é freqüentemente palco de surgimento de novos destinos turísticos. Passar-se-á à análise do caso de um destino turístico de litoral ainda em formação.

\section{ESTUDO DE CASO: A PRAIA DE GAMELA E A CO- MUNIDADE DE PESACADORES DE AVER-O-MAR (BARRA DE SIRINHAÉM/PE)}

Composta por 21 municípios, a Zona Costeira de Pernambuco abriga $44 \%$ da população do Estado (3.545.000 habitantes). Com uma linha de costa de 187 km de extensão, inicia-se no município de Goiana, ao norte (fronteira com o Estado da Paraíba), e segue até o município de São José da Coroa Grande, ao sul (limitando-se com o Estado de Alagoas).

O município de Sirinhaém está localizado na Mesorregião da Mata Pernambucana, Microrregião da

\footnotetext{
4 "Muitas das ações que se exercem num lugar são o produto de necessidades alheias, de funções cuja geração é distante e das quais apenas a resposta é localizada naquele ponto preciso da superfície da Terra" (SANTOS, 2004a, p.80).
} 
Mata Meridional, a $79 \mathrm{~km}$ do Recife (capital do Estado) nas coordenadas geográficas: $8^{\circ} 35^{\prime} 27^{\prime \prime}$ de Latitude Sul e $35^{\circ} 6^{\prime}$ '58" de Longitude Oeste. Limita-se ao Norte com Ipojuca e Escada; ao Sul com Rio Formoso e Tamandaré; a Leste com o Oceano Atlântico e a Oeste com Ribeirão.

Buscando aproveitar o potencial cênico dos recursos naturais do litoral sul e com vistas a diversificar a economia local, extremamente dependente da canade-açúcar, o Governo do Estado apresentou, no início da década de 1990, o Programa de Desenvolvimento do Turismo no Nordeste (Prodetur/NE). Em sua primeira fase (1994-2005), o Prodetur/NE em Pernambuco, via BNB (Banco do Nordeste), canalizou recursos do Banco Interamericano de Desenvolvimento (BID) - cerca de US\$ 42 milhões -, para implementar o Centro Turístico de Guadalupe (CTG).

Abrangendo os Municípios de Sirinhaém, Rio Formoso e Tamandaré, esse projeto visou desenvolver um pólo turístico voltado para a captação da demanda internacional interessada em visitar balneários tropicais. Embora o projeto do CTG como um todo não tenha se efetivado conforme o planejado, a perspectiva de cons- trução de resorts na área permanece. A cadeia portuguesa de hotéis Dorisol tem projeto para a construção de outro resort na praia de Sirinhaém e, segundo o gerente de operações da rede no Brasil, "o terreno está definido e já temos uma construtora interessada. A busca agora é por investidores" 5 .

Com as mesmas intenções, o grupo $\mathrm{JCPM}^{6}$ adquiriu em 2005 uma área de 120 hectares na Praia de Guadalupe. Segundo o presidente do Grupo, "a meta é atingir um público que procura serviços de luxo, provavelmente em parceria com alguma grande cadeia hoteleira internacional". Vê-se, portanto, que independentemente de haver logrado sucesso, os planos de se desenvolver uma "nova Cancun" no litoral nordestino ainda são acalentados.

Em Barra de Sirinhaém localizam-se as principais estruturas do CTG, a saber: um heliporto (Figura 1) e um píer (Figura 2) e as Praias de Guaiamum, Guadalupe e Gamela, sendo esta última, o objeto de investigação do presente estudo. Isso porque, segundo Selva et al. (2006, p. 3), esta praia (Figura 3) é palco de um conflito entre a comunidade local de pescadores e a perspectiva futura de desenvolvimento do turismo.

FIGURA 1 - HELIPORTO DESATIVADO (BARRA DE SIRINHAÉM - PE)

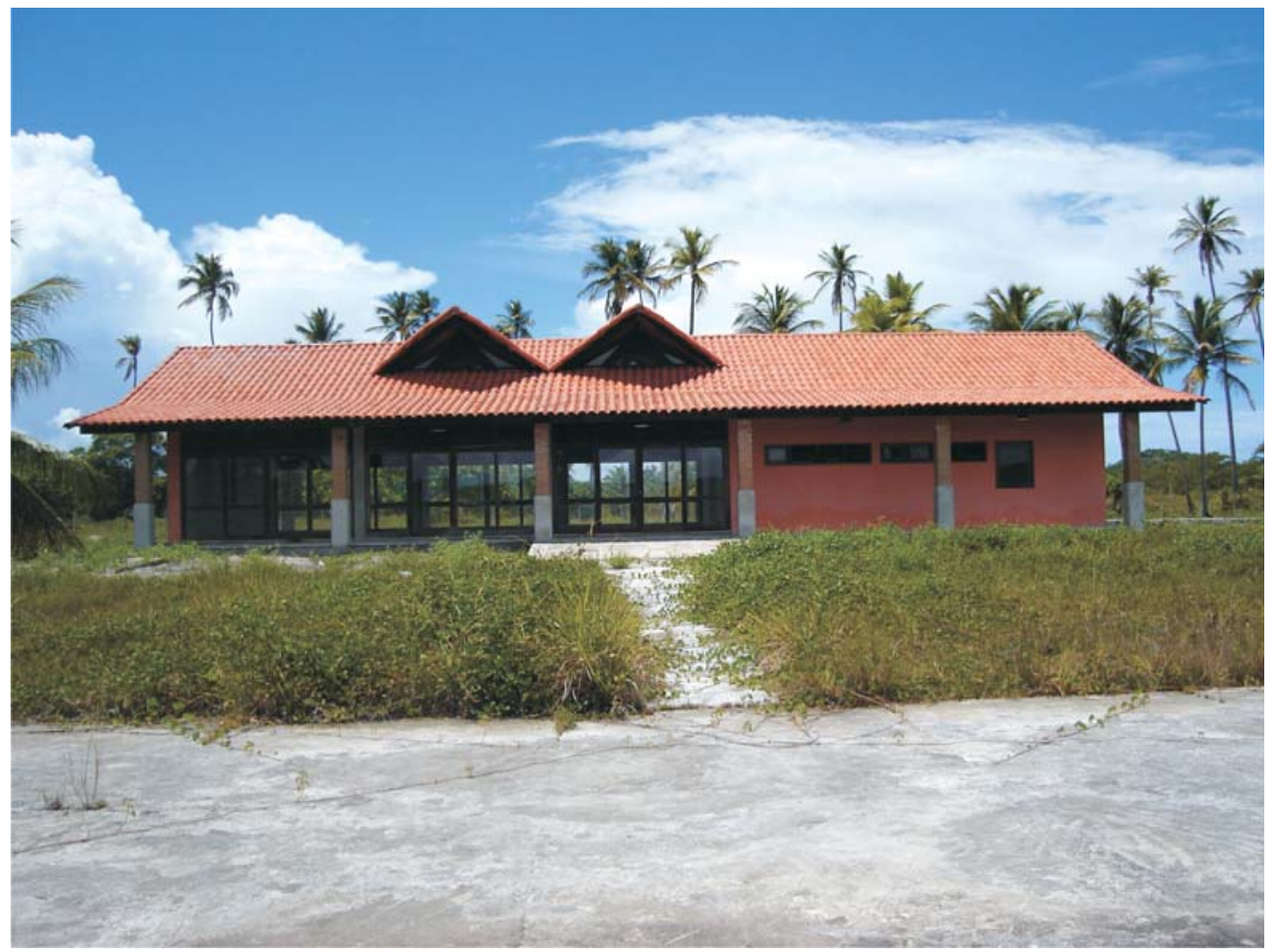

FONTE: O AUTOR (2006) são e jornal).

${ }^{5}$ Fonte: «http://www.mercadoeeventos.com.br/script/FdgDestaqueTemplate.asp?pStrLink=1,28,0,9811\&IndSeguro=0»

6 O grupo JCPM, é um grupo pernambucano que tem investimento em Shoppings Centers, no setor de comunicação (rádio, televi- 
FIGURA 2 - PÍER NA FOZ DO RIO FORMOSO (COMUNIDADE DE MARIAÇU; BARRA DE SIRINHAÉM - PE)

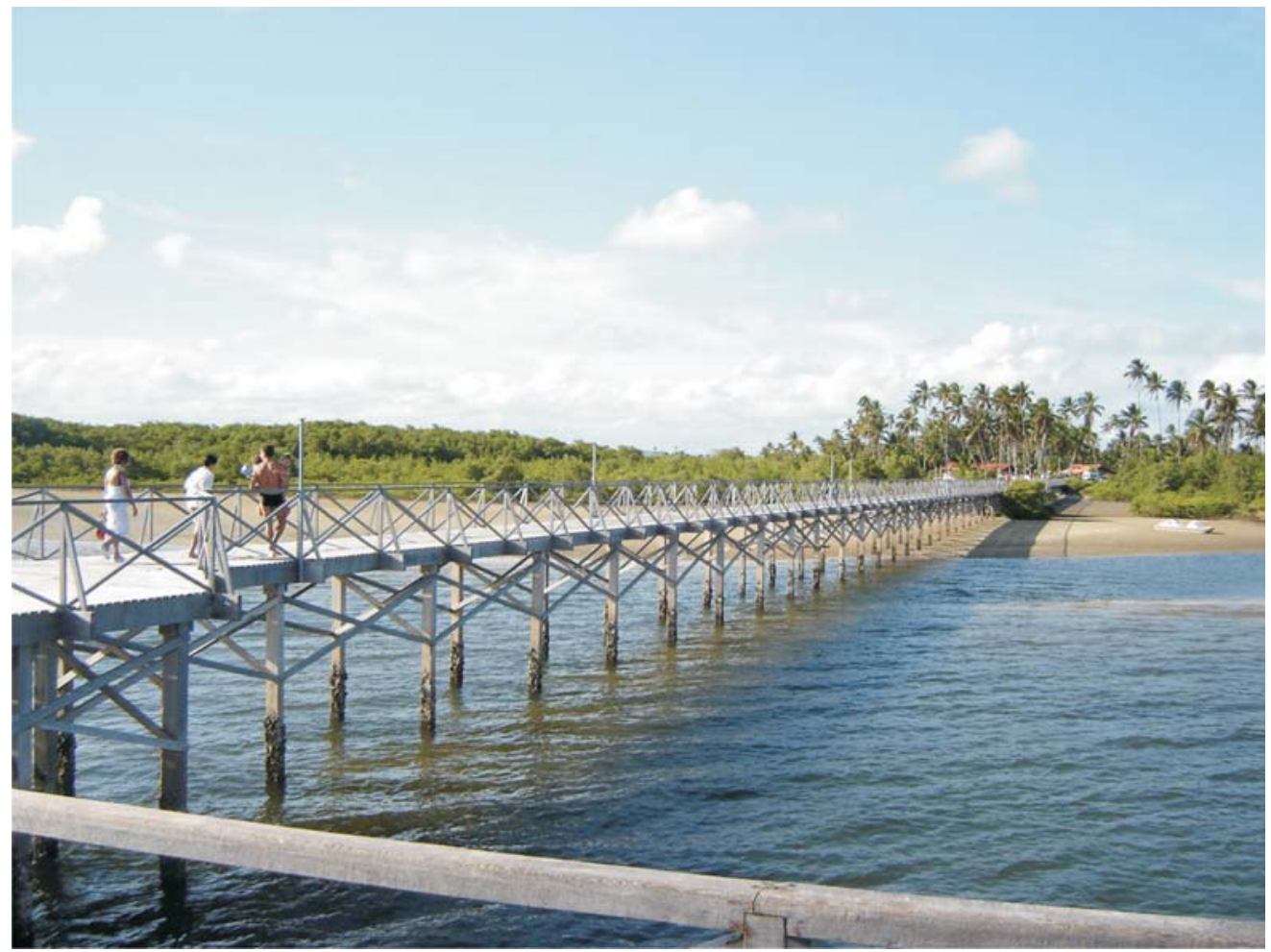

FONTE: O AUTOR (2006)

FIGURA 3 - LOCALIZAÇÃO DA VILA DE AVER-O-MAR

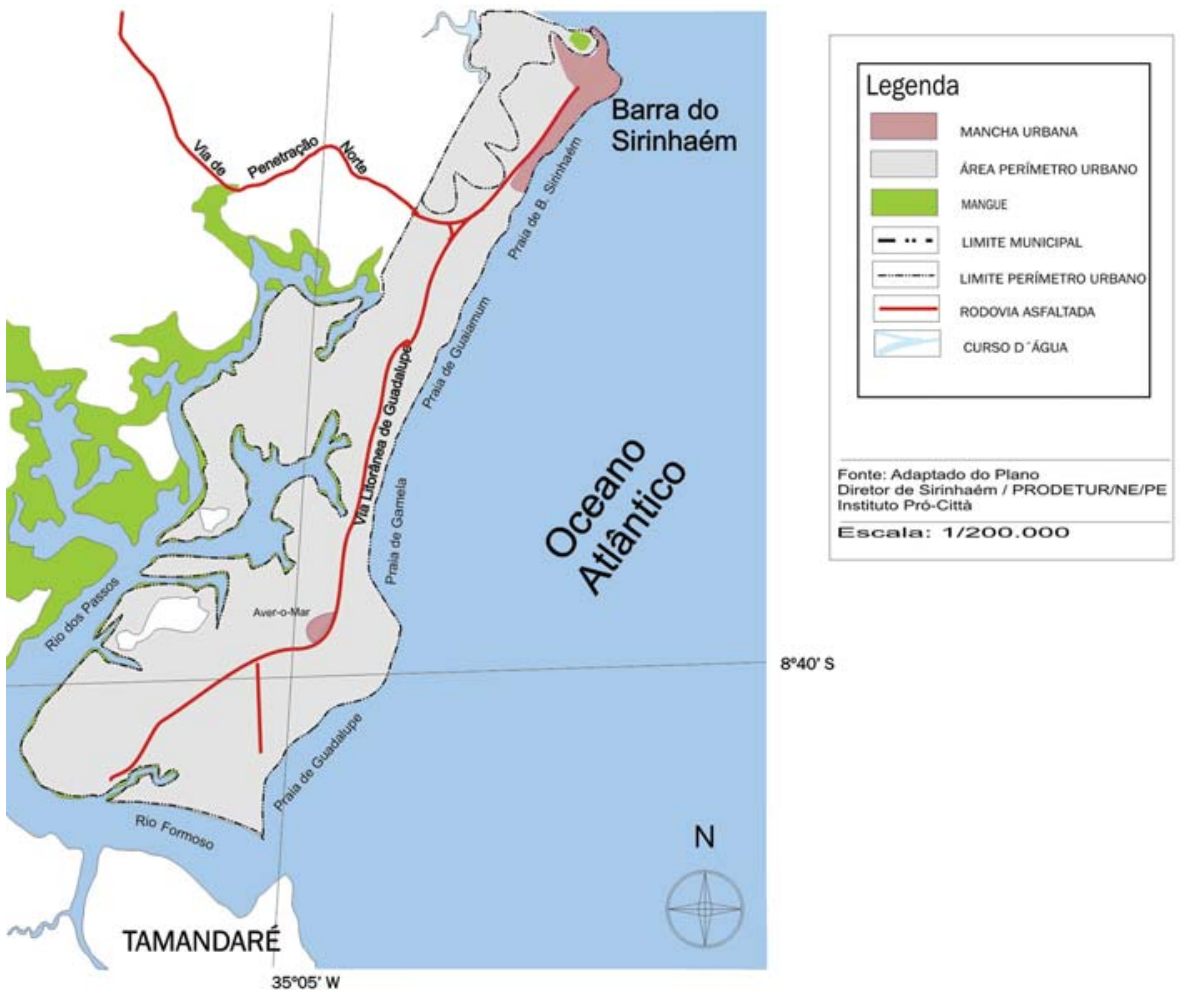

FONTE: ADAPTADO DO PLANO DIRETOR DE SIRINHAÉM 
Durante décadas a Praia de Gamela foi um local onde viveram e trabalharam alguns pescadores de comunidades da Barra de Sirinhaém. Em meados da década de 1970 as terras foram compradas por um empresário de origem portuguesa ${ }^{7}$ e os nativos foram obrigados a se mudar para uma vila comunitária a alguns metros de onde viviam originalmente.

A Vila de Aver-O-Mar, como é chamada, é parte do um grande loteamento homônimo que compreende uma porção contínua de terras entre Guadalupe (ao sul) e a área urbanizada de Barra de Sirinhaém (ao norte). O objetivo da Vila foi desocupar a faixa de praia para a futura especulação imobiliária.

Atualmente cerca de 148 famílias (600 pessoas) vivem na vila, sendo 150 crianças (até 11 anos de idade) e 470 adultos $^{8}$ e as principais atividades desempenhadas são: pesca no mar (realizada pelos homens), pesca de mariscos (por mulheres) e a pequena roça de subsistência. Contudo, nota-se mais recentemente o surgimento de novas ocupações, tais como: o trabalho doméstico (para as mulheres) e de vigia (para os homens jovens) em casas de veraneio, ainda que, a julgar pelo índice da função turística de Defert $^{9}$ (PEARCE, 2003 , p. 185), se constate que o turismo na área é considerado incipiente ${ }^{10}$.

A infra-estrutura da Vila compreende: casas de alvenaria, telefones públicos, posto de saúde, templos evangélicos, local coberto usado para a comunidade se reunir, campo de futebol, escola, padaria e ruas asfaltadas. Saneamento básico ainda inexiste e o sistema de transporte público é deficiente, opera com apenas um ônibus (que faz a linha: Aver-O-Mar-Sirinhaém, passando pelo centro de Barra do Sirinhaém e pelo povoado de Santo Amaro) e que, segundo os moradores, tem horários inconvenientes.

Embora tenham perdido seu espaço à beira-mar (as referências a esse evento têm, por parte dos mais velhos, um tom saudosista), a grande maioria dos pescadores interpretou a mudança para a Vila de forma positiva. A razão disso ficou evidente ao longo das entrevistas: infra-estrutura básica. O fato de haver luz elétrica, casas de alvenaria e ruas asfaltadas na Vila foram os principais atrativos que levaram os pescadores a abrir mão da área à beira-mar. Com efeito, a construção da Vila de Aver-O-Mar foi parte de um estratagema que buscou realizar uma desocupação nãoconflituosa da faixa de praia.

Evitado na época, o conflito hoje se torna incontornável. Isso porque a supervalorização fundiária imposta, em parte pela instituição do CTG, ocasionou uma busca acentuada por segundas residências. A opção mais cômoda para os que não queriam comprar um terreno e construir uma casa de veraneio foi a de comprar as casas da Vila e reformá-las. De acordo com o próprio administrador de Aver-O-Mar, um terreno de $10 \times 25 \mathrm{~m}^{2}$ na Vila custa entre $R \$ 5.000,00$ e $R \$ 8.000,00$ e já podem ser verificadas casas que foram compradas para servirem como segundas residências. Na beiramar, os terrenos (a depender das dimensões) variam entre $R \$ 40.000,00$ e $R \$ 70.000,00$.

O que chama atenção nesse caso é o fato de que, quando foram relocados da praia para a Vila, os pescadores não receberam os títulos de propriedade da terra, tampouco das casas. Assim, não encontram respaldo jurídico para permanecerem em suas residências. Isso vem gerando sérias discussões entre os empresários proprietários da Vila e os pescadores. Em entrevistas, os pescadores afirmaram sofrer sérias pressões para deixarem o local, mas a falta de um lugar para onde ir é o que os mantém.

A situação desses pescadores é agravada na medida em que se constata que as políticas governamentais direcionadas para o aproveitamento turístico do litoral de Gamela não vislumbraram a participação ativa

7 De acordo com o sr. Luís Paulo - administrador da Vila de Aver-O-Mar (pessoa contratada para gerir os loteamentos da Vila e as fazendas de coco) -, o empresário português Aldemiro Martins Gomes Moreira veio para o Brasil com cerca de 14 anos. Aqui, seus pais abriram uma padaria e o jovem Aldemiro começou a trabalhar entregando os pães. Com o passar do tempo abriu outros negócios, dentre os quais uma agência de automóveis e uma pedreira. Por volta de 1975, em associação com seu irmão (sr. Fernando Moreira), comprou uma grande porção de terras em Barra de Sirinhaém e fez o loteamento. O nome da Vila é uma homenagem à sua cidade natal: Aver-O-Mar, uma Freguesia do Concelho de Póvoa do Varzim, na Região (porção norte de Portugal).

${ }^{8}$ Dados fornecidos pela Associação de Moradores e Pescadores de Aver-O-Mar.

9 Segundo BARROS (1998) "O índice reflete a intensidade da função turística hoteleira em uma área estudada. Em outras palavras, a turistização. Ele indica o grau de dependência e vulnerabilidade de determinada área aos ritmos, expansões e retrações dos fluxos turísticos".

${ }^{10} \mathrm{O}$ índice da função Turística de Defert [T (f)] é conseguido comparando-se o número de leitos (N) disponíveis para turistas naquela área com a população residente $(\mathrm{P})$ de acordo com a fórmula: $\mathrm{T}(\mathrm{f})=\mathrm{N}$ x 100 / P. Assim, de acordo com os dados obtidos in loco: $\mathrm{T}(\mathrm{f})=30 \mathrm{x}$ $100 / 600$, ou seja, $T(f)=5$. Segundo a classificação proposta por Boyer (apud PEARCE, 2003, p. 185), este índice equivale dizer que existe "pouca atividade turística". 
dessas pessoas. As diretrizes formuladas pelo Prodetur/ NE I (BNB, 2005, p. 6) mencionam: a) atrair atividades turísticas privadas adicionais e de melhor padrão; b) gerar oportunidades de emprego; c) melhorar os níveis de renda; d) aumentar as receitas públicas; e) beneficiar a população de baixa renda das áreas selecionadas com disponibilização dos serviços de abastecimento de água, esgotos e acessos pavimentados e f) aumentar a capacidade dos Estados beneficiados de acompanhar a demanda por serviços básicos ${ }^{11}$.

Embora os resultados dessas intervenções tenham gerado alguns benefícios, ainda assim foi insuficiente para que se pudesse falar de um efetivo sucesso do Programa. Os próprios estudos de avaliação da primeira fase do Prodetur/NE realizados pelo BID evidenciaram que, sobretudo na área social e ambiental, nem sempre os investimentos realizados tiveram efeitos positivos. Segundo Coriolano (2006, p. 47), isso ocorre (continuará a ocorrer) porque "a população residente no núcleo receptor é negada nas políticas, sequer considerada no planejamento, nas decisões, embora sendo elemento-chave no sistema turístico".

Com efeito, o próprio BNB (2005, p. 69) considera que uma das principais lições aprendidas com o Prodetur/NE em sua primeira fase foi que

a efetiva participação social na implementação do Programa deve ser almejada, buscando-se não somente criar diferentes mecanismos de participação da sociedade beneficiária no planejamento e execução das ações, mas também tornar os mecanismos criados eficientes na extração de informações relevantes para a correção de rumos na gestão do Prodetur/NE.

Acrescentar-se-ia ainda que ser ouvida é só o primeiro passo. A população local deve chamar para si a responsabilidade sobre os rumos do turismo em seu espaço e isso não se faz sem um "fortalecimento horizontal" com o mínimo de "ações localmente constituídas" de que fala Santos (2004a, p. 288).

Diante dos fatos pode-se trabalhar com dois cenários para Aver-o-Mar: no primeiro deles, supõe-se que o poder estrangeiro seja mais forte e a comunidade de pescadores se veja obrigada a deixar em definitivo o local, na medida em que o turismo vá se consolidando até chegar ao ponto em que a pressão sobre os pescadores seja demasiada. No segundo cenário, trabalhase com a hipótese de os pescadores se organizarem e conseguirem se fortalecer ao ponto de conseguirem se manter na Vila. Nesse caso, os moradores iriam se de- parar com o cenário futuro planejado para Gamela. Segundo o zoneamento definido pelo Projeto Costa Dourada, toda a faixa litorânea da Praia de Gamela será destinada à construção hoteleira do tipo resort, pois tanto o Prodetur/NE como o Plano de Desenvolvimento do Turismo em Pernambuco - Projeto Costa Dourada entendem que essa é a melhor alternativa para o aproveitamento turístico da área.

Resort, segundo a Associação Brasileira de Resorts,

é um empreendimento hoteleiro de alto padrão em instalações e serviços, fortemente voltado para o lazer em área de amplo convívio com a natureza, na qual o hóspede não precise se afastar para atender suas necessidades de conforto, alimentação, lazer e entretenimento.

Parte da estratégia que incentiva o hóspede a permanecer no hotel a maior parte do tempo é a adoção do sistema "tudo incluso" (all inclusive), que no entendimento de Gutiérrez (2002, p.117) "é um produto para destinos de praias". Nesse tipo de empreendimento o hóspede paga, antecipadamente, por todas as despesas de sua estada. Assim, já tendo pago antecipadamente pela utilização dos equipamentos do resort, o hóspede sente-se no direito de usufruí-lo o máximo que puder, o que implica seu confinamento.

Sem contato direto com a população local, uma vez que são incentivados a permanecer o máximo de tempo possível no hotel, não se produzem as condições necessárias para a população local adquirir renda a partir do turismo. A única opção de se trabalhar com o turismo é via resort, como fornecedor, seja de produtos ou de força de trabalho.

Observando o caso da Praia de Gamela, percebe-se que a tradicional alegação do turismo como atividade dinamizadora e geradora de renda merece ser mais cautelosamente analisada. Considerando que o espaço turístico pretendido é do tipo resort, é de se esperar um completo alijamento da comunidade local no processo de gestão da atividade. Nesses termos, o turismo pouco ou nada melhorará as condições de vida da comunidade local, uma vez que estará voltada a atender aos interesses das elites estrangeiras. De certa forma, pode-se dizer que os resorts que se pretendem instalar em Gamela se assemelhariam a "palácios colossais que surgem por toda parte" e que "representam a pura racionalidade sem sentido dos grandes cartéis internacionais" (ADORNO, 2002, p. 7).

\footnotetext{
${ }^{11}$ http://www.bnb.gov.br/content/aplicacao/prodetur/prodetur_ne1/gerados/objetivos.asp
} 
Sobre a produção do espaço turístico, a condução desse estudo permitiu inferir que esta se dá tanto pela atribuição de novas funções a antigas formas, quanto pela construção de novas formas que acabam por alterar as estruturas locais presentes. O que há de marcante nisso tudo é que estas novas formas e funções sempre foram, e continuam a ser, alheias às necessidades locais. Ou seja, o objetivo é produzir um espaço aprazível aos olhos do turista, de modo que se construa "um complexo de imagens, atores e territórios para que a exploração possa ser efetivada" (ALMEIDA, 1999, p. 185).

Trata-se, portanto, de uma verdadeira refuncionalização do espaço que visa transformar o espaço do pescador em lugar do veraneio e dos hotéis. Nesta nova configuração espacial instaurada pelo turismo, inauguram-se relações de poder entre a comunidade local e certos agentes externos, que, ao contrário do que prega a ideologia desenvolvimentista do turismo, não rendem resultados positivos para os primeiros.

Nessas circunstâncias, cessa de existir o espaço como lócus de reprodução de suas relações sociais e emerge uma espécie de espaço alienado, onde as relações entre suas componentes (quando existem) não são espontâneas. São estes efeitos que começam a se delinear na comunidade de pescadores de Aver-o-Mar.

\section{CONCLUSÕES}

O lugar turístico é produto da sociedade de consumo e sua constituição busca tão somente gerar um produto a ser comercializado: uma mercadoria. O estudo do caso de Gamela permitiu identificar uma série de eventos que fornecem indícios de como isso ocorre no litoral nordeste do Brasil.

Todavia, deve-se advertir que, por se tratar de um estudo de caso, os resultados apresentados neste trabalho são aplicáveis à Praia de Gamela strictu sensu. Embora cada lugar seja único ${ }^{12}$, observaram-se alguns pontos comuns que, coeteris paribus, autorizam propor uma generalização sobre o processo de produção do espaço turístico litorâneo no a Região Nordeste.

Salvo variáveis que operem na escala local (sobretudo no que se refere ao grau de organização da comunidade), sugere-se que o espaço turístico no litoral do Nordeste tende a ser produzido segundo o seguinte esquema: a construção de uma ideologia que reserva o espaço para o aproveitamento turístico e torna possível a constituição de uma imagem estereotipada. A consolidação dessa imagem estimula o fluxo turístico que é mantido graças à conversão do espaço em um simulacro, no qual o turista encontra-se inebriado num ambiente espetacular. Esse ambiente, ao mesmo tempo em que é produto de mentes alienadas, cria situações favoráveis a um processo de alienação espacial.

\section{PRODUÇÃO DO ESPAÇO TURÍSTICO EM GAMELA}

Grosso modo, poder-se-ia dizer que a produção do espaço turístico em Gamela se dá através da alteração na estrutura do local, seja por meio da refuncionalização de velhas formas (casa dos pescadores para alugar); pela produção de novas formas (resorts) ou pela extinção de velhas formas (casas dos pescadores a beira-mar). No entanto, essa interpretação é por demais simplória, afinal

o espaço não pode ser estudado como se os objetos materiais que formam a paisagem trouxessem neles mesmos sua própria explicação (SANTOS, 2004b, p. 58).

Nesse sentido, a advertência de Santos é assaz pertinente:

quando analisamos um dado espaço, se nós cogitamos apenas dos seus elementos, da natureza desses elementos ou das possíveis classes desses elementos, não ultrapassamos o domínio da abstração. É somente a relação que existe entre as coisas que nos permite realmente conhecê-las e defini-las. Fatos isolados são abstrações e o que lhes dá concretude é a relação que mantêm entre si. (SANTOS, 1985, p. 14)

\section{LEGITIMAÇÃO IDEOLÓGICA}

A realização deste experimento permitiu entrever que o processo de produção do espaço turístico iniciase pela ideologia, pois "sem o domínio do espaço o turismo não pode se realizar" (CORIOLANO, 2006, p. 23). Mediante a cristalização da idéia de que o turismo é a opção natural para as áreas litorâneas busca-se consolidar a atividade como a melhor, senão única, opção para

\footnotetext{
12 "Cada lugar é marcado por uma combinação técnica diferente e por uma combinação diferente dos componentes do capital, o que atribui a cada qual uma estrutura técnica própria, específica, às quais corresponde uma estrutura própria, específica, do trabalho [...] isso resulta do fato de que cada lugar é uma combinação de técnicas qualitativamente diferentes, individualmente dotadas de um tempo específico - daí a diferença entre os lugares" (SANTOS, 1985, p.12-13).
} 
o desenvolvimento (sustentável) das comunidades litorâneas ${ }^{13}$, embora Krippendorf (2003, p.98) reconheça que "os meios envolvidos começam a compreender que uma economia que se apóia apenas no setor turístico é muito mais frágil que uma economia multissetorial".

Assim, antes de firmar-se concretamente através das novas formas espaciais, o turismo parece fixar-se abstratamente como possibilidade de desenvolvimento local para o Nordeste brasileiro, região conhecida "mundialmente como foco de pobreza na América Latina" (CORIOLANO, 2006, p. 49). Esse argumento ganha ainda mais força quando acompanhado pela idéia de que o turismo é uma "indústria limpa" ou que é a via mais segura para o aproveitamento sustentável dos recursos naturais.

Assim, não só existe a idéia de que o turismo é a melhor opção para o aproveitamento dos recursos naturais, como também o modelo de resorts é a via pela qual o turismo deve ser desenvolvido. Percebe-se, portanto, que a legitimação da vocação natural da praia para o turismo traz consigo, como um Cavalo de Tróia, o modelo a ser seguido. Consolidada a idéia de que o turismo pode ser a melhor alternativa para o desenvolvimento local, torna-se imperativo a formação de uma imagem.

\section{FORMAÇÃO DA IMAGEM}

Como destaca Mészáros (2006, p. 91), "as lendas são fáceis de inventar e difíceis de descartar". Neste sentido, é imperativo ao funcionamento da ideologia que, subjacente à idéia do turismo como a melhor opção, venha uma outra: a de que a transformação de espaços naturais em destinos turísticos é um evento natural. Sobre isto, é prudente lembrar que não se deve aceitar "o que é de hábito como coisa natural, pois em tempo de desordem sangrenta, de confusão organizada, de arbitrariedade consciente, de humanidade desumanizada, nada deve parecer natural nada deve parecer impossível de mudar"14.

Com efeito, não há o que se chama de uma "vocação natural" do litoral para o turismo. O que existe é a construção social de uma imagem do paraíso na Terra, utilizada para reconfortar os espíritos enfraquecidos e instigar o consumo ${ }^{15}$. Construiu-se, como defende Coriolano (2006, p.24), um “'mito de Pasárgada': onde a felicidade implica no deslocamento para lugares desconhecidos [onde] a viagem leva à aventura, proporciona alto índice de satisfação, de negação da tristeza e dos problemas cotidiano".

Ocorre, como defende Ouriques (2005, p. 61), que

somente sob certas condições é que os lugares se tornam uma destinação turística. Somente quando as relações capitalistas se instalam é que os rios, as montanhas, as praias e as dunas passam a ser apropriados economicamente pelo turismo.

A imagem do CTG como uma alternativa ao Caribe ilustra bem as pretensões de se criar uma imagem de paraíso tropical em Pernambuco a ser veiculada e comercializada no mercado consumidor europeu. Para isso são recorrentes os clichês: "oceano de um azul profundo, areia branca, pôr-do-sol, palmeiras, belos turistas bronzeados, aldeias de pescadores [...] piscinas azul-turquesa, sol eterno" (KRIPPENDORF, 2003, p. 42-43).

Percebe-se, pois, que a produção de um espaço turístico nunca é desinteressada, visto que "as formas espaciais produzidas pela sociedade manifestam projetos, interesses, necessidades, utopias" (MORAES, 2005, p. 22). Longe de ser uma vocação natural para lugares de significativa beleza cênica, o turismo configura-se "como um processo de produção de um complexo de imagens, atores e territórios para que a exploração possa ser efetivada" (ALMEIDA, 1999, p. 185).

\section{ESPETACULARIZAÇÃO}

Após a legitimação da atividade turística como atividade por excelência para as áreas litorâneas seguida da consolidação da imagem do destino, há a necessidade de reafirmar o mito do paraíso; fazer com que o turista, de fato, encontre o que veio buscar. Trata-se de uma seqüência lógica, pois, vendo o que veio esperando ver, o turista encontra-se realizado e isso aumenta as possibilidades de retorno, o que torna o ciclo de visitação viável no médio/longo prazo.

\footnotetext{
13 "Lugar-comum nos discursos governamentais e de muitas entidades, o turismo como vocação nacional insuficientemente explorada ganhou a mídia e os eventos dos mais diversos tipos, especialmente quando o assunto é desenvolvimento - de preferência com o adjetivo 'sustentável'” (SALVATI, 2004, p. 25).

14 "Nada é impossível de mudar", de Bertolt Brecht.

15 "Os paraísos tropicais do Terceiro Mundo não somente correspondem a expectativas de uma parcela significativa da demanda mundial de turistas [...] como também rendem-se facilmente, aos apelos mercadológicos da atividade, cuja sedução maior está nos fatores geração de renda e geração de emprego" (CRUZ, 2002, p. 133).
} 
Para tanto é mister criar um microambiente, um simulacro onde o turista perceba todos estímulos que o atraíram. Trata-se, verdadeiramente, de uma espetacularização, na qual o "parecer" sucede o "ter" (que por seu turno, já havia substituído o 'ser'). Contudo, como observa Debord (1997, p. 2): "o espetáculo não é um conjunto de imagens, mas uma relação social entre pessoas, mediatizada por imagens". Assim, pode-se afirmar que o espaço turístico é espetacular na medida em que tem suas relações sociais governadas por imagens estereotipadas,

Nesse espaço espetacularizado,

o turista guarda sua distância, e veda a distância de se reduzir à proximidade. É como se cada um deles estivesse trancado numa bolha de osmose firmemente controlada; só coisas tais como as que o ocupante da bolha aceita podem verter para dentro, só coisas tais como as que ele ou ela permitem sair podem vazar (BAUMAN, 1994, p. 114).

É neste cenário que o turista se sente seguro, pois pode exercer o que o próprio Bauman (1994) denomina de "controle situacional", ou seja, "a aptidão para escolher onde e com que parte do mundo 'interfacear', e quando desligar esta conexão". É o que Krippendorf (2003) vai chamar de "bolha turística".

Até mesmo "a dimensão cultural do turismo", enfatiza Coriolano (2006, p. 31),

é substituída por uma função puramente comercial, pois o viajante encontra em qualquer parte do mundo os espaços similares e termina viajando numa seqüência de reproduções artificiais do mundo dos cartões postais, que a publicidade apresenta com sucesso.

Fica evidenciada, portanto, a relação que se estabelece entre ideologia, imagem e espetáculo; atuam de forma recíproca, retroalimentando-se e somando-se para desencadear o que se poderia chamar de um espaço alienado. Nada mais óbvio, haja vista que na qualidade de mercadoria, o espaço turístico torna-se automaticamente alienável.

\section{ALIENAÇÃO}

Considerando que o espaço turístico é produzido para o visitante e sem ignorar o fato de que, não raro, é habitado por comunidades locais, é razoável supor que o espaço alienado exerça influência sobre esses dois sujeitos.

Para o primeiro grupo, o espaço é entendido consoante à visão de quem está dentro da "bolha turística" e, ao negar, ainda que temporariamente, os elementos caóticos do mundo real, o turismo prioriza a fantasia (CORIOLANO, 2006, p. 24). Nesse cenário, o visitante passa a crer que a paisagem que vê é legítima e aceita como verdadeira a cultura mimetizada em espetáculos. Neste simulacro deixa-se levar e, desta forma, o espaço turístico elitista se mantém e prospera num modelo de McDisneyfication ${ }^{16}$. Ao aceitar a utopia, o turista vive o simulacro como se fosse real e, "isolado[s] de um ambiente acolhedor e das pessoas locais [...] não levam em consideração o mundo 'real' em torno deles" (URRY, 1996, p. 23) e nesse sentido "as alienações são renovadas nas novas formas de consumo, que se acredita trazerem felicidade" (CORIOLANO, 2006, p. 31).

Já o segundo grupo presencia a emergência de um "espaço que não ajudou a criar, cuja história desconhece, cuja memória lhe é estranha" e nesse sentido "esse lugar é a sede de uma vigorosa alienação" (SANTOS, 2004a, p. 328).

\section{ALGUMAS CONSIDERAÇÕES FINAIS ACERCA DO PROCESSO DE PRODUÇÃO DO ESPAÇO TURÍSTI- CO NO LITORAL}

De forma resumida, observou-se que a refuncionalização de algumas formas e o (des)aparecimento de outras é a materialização de um processo de turistificação iniciado com a criação da ideologia de que a "vocação natural" dos espaços litorâneos é o turismo. A isto, segue-se a formação de uma imagem estereotipada da praia como paraíso tropical. Em seguida, há um esforço para tornar real tudo o que até então havia sido produzido no domínio da idéia e do desejo. Para isto espetaculariza o espaço e suas relações. Ao final desse processo gera-se uma espécie de espaço alienado onde o nativo (pescador) não reconhece o lugar, o turista vive uma fantasia e o próprio espaço perde sua identidade.

Como derradeira conseqüência do processo de produção do espaço turístico de litoral, há a criação de um espaço alienado, "sem história, sem identidade; [...] espaço do vazio. Ausência. Não-lugares" (CARLOS, 1999, p. 28). O espaço, portanto, deixa de existir como um lócus de convergência de fatores autênticos e tor-

16 "Ritzer e Liska [...] aplicaram a idéia de 'MacDisneyfication' ao turismo de massa em pacotes que oferecem férias totalmente previsíveis, padronizadas, eficientes, calculáveis e controladas" (TORRES, 2002, p. 12). 
na-se uma mimetização, uma encenação para entreter o visitante. $O$ que há de mais curioso nisso tudo é que este processo ocorre com a conivência do aparelho estatal.

Evidentemente, cabe não olvidar que todo esse processo tende a ser acelerado num mundo globalizado. Ou seja, à medida que as relações se ampliam numa escala sem precedentes, e num momento no qual a informação circula numa velocidade inimaginável, os menores lugares, e com eles suas populações, tendem a se converter em mercadorias.

O estudo do caso de Gamela foi útil pois evidenciou que, sob a alegação do desenvolvimento (sustentável), as comunidades locais são alijadas do processo de produção de seus próprios lugares, convertidos, pelo turismo, em

simulacros, não-lugares, ilhas da fantasia [...] e não são esses lugares que constroem as pessoas, mas, ao contrário, eles são traduções espaciais de anseios de uma dada parcela da sociedade mundial (CRUZ, 2002, p. 136).

Diante do exposto, não é exagero dizer que o turismo, do modo como vem sendo praticado no litoral sul de Pernambuco, tende a gerar uma segregação socioespacial, com conseqüente impacto negativo sobre a estrutura familiar dos pescadores (CORDEIRO; FIRMINO, 2005, p. 7). Mais incisivamente, pode-se dizer que isso ocorre com a anuência das próprias autoridades públicas que, iludidas por um modelo de turismo

\section{REFERÊNCIAS}

ADORNO, Theodor. Indústria cultural e sociedade. São Paulo: Paz e Terra, 2002.

ALMEIDA, Maria Geralda. Turismo e novos territórios no litoral cearense. In: RODRIGUES, Adyr (Org.). Turismo e geografia: reflexões teóricas e enfoques regionais. 2. ed. São Paulo: Hucitec, 1999. p. 184-190.

BARROS, Nilson. Manual de geografia do turismo: meio ambiente, cultura e paisagens. Recife: Editora Universitária da UFPE, 1998.

BAUMAN, Zygmunt. O mal-estar da pós-modernidade. Rio de Janeiro: Jorge Zahar, 1998.

BANCO DO NORDESTE DO BRASIL S. A. Relatório final de projeto: programa de desenvolvimento do turismo no nordeste: primeira fase. Prodetur/NE. Fortaleza, 2005.

Prodetur: ampliando as atividades turísticas no nordeste. Disponível em: <http://www.bnb.gov.br/content/ elitista, tendem a entender "desenvolvimento turístico" e "construção de grandes hotéis" como sinônimos. Insistindo-se nesse modelo de turismo para o litoral, a tendência é que a tomada do controle pelas forças verticais mine o controle dos pescadores sobre seu próprio espaço, fazendo com que eles sejam relegados à "mera condição de figurantes ou espectadores de uma peça que não pediram para assistir" (FONTELES, 2004, p. 35).

Considerando que "as comunidades locais têm o direito de manter e controlar a sua herança cultural e assegurar que o turismo não tenha efeito negativo sobre ela" (SALVATI, 2004, p. 17), acredita-se que uma boa alternativa a ser tentada é a do empowerment da população local e da criação de uma política de incentivo à construção e capacitação gerencial para equipamentos turísticos de pequeno porte (pousadas e restaurantes) pertencentes aos próprios pescadores. Afinal, como dizia Schumacher (1983): "small is beautiful". Aliás, no contexto deste trabalho, até mesmo o título brasileiro para o livro parece ser ainda mais oportuno: "o negócio é ser pequeno".

Por fim, resta deixar bastante claro que não foi, em momento algum, intenção deste trabalho criticar, tampouco desacreditar, as possibilidades do turismo como vetor de desenvolvimento. No entanto, acreditase tal como Selva et al (2006) que um desenvolvimento turístico genuinamente sustentável, ou seja, que conserve o meio ambiente litorâneo utilizável para as futuras gerações, só poderá ser alcançável com a tomada de poder pela comunidade local.

aplicacao/PRODETUR/Apresentacao/gerados/ apresentacao.asp>. Acesso em: 22/3/2006.

BENI, Mário Carlos. Análise estrutural do Turismo. 7. ed. São Paulo: Senac, 2002.

CARLOS, Ana Fani. O turismo e a produção do não-lugar. In: YÁZIGI, Eduardo; CARLOS, Ana Fani; CRUZ, Rita de Cássia (Orgs.). Turismo: espaço, paisagem e cultura. 2. ed. Hucitec, 1999. p. $25-37$

CORDEIRO, Itamar; FIRMINO, Fabiana. Consideraciones sobre la globalización del turismo en el litoral sur de Pernambuco (Brasil): uma contribución a las estratégias de desarrollo sostenible. In: VII CONGRESO NACIONAL Y I INTERNACIONAL DE INVESTIGACIÓN TURÍSTICA, 2005, Guadalajara y Zapopan (México). p. 13.

CORIOLANO, Luzia Neide. O turismo nos discursos, nas políticas e no combate à pobreza. São Paulo: Annablume, 2006. 
CORDEIRO, I. D. e.; CASTILHO. C. A (re)produção do espaço a...

CRUZ, Rita. Política de turismo e território. São Paulo: Contexto, 2002.

DEBORD, Guy. A sociedade do espetáculo. Rio de Janeiro: Contraponto, 1997.

DIEGUES, Antônio Carlos; ARRUDA, Rinaldo (Orgs.). Saberes tradicionais e biodiversidade no Brasil. São Paulo: MMA/ USP, 2001.

FONSECA, Maria Aparecida; COSTA, Ademir. A racionalidade da urbanização turística em áreas deprimidas: o espaço produzido para o visitante. Mercator. revista de Geografia da UFC, Fortaleza, n. 6, ano 3, p. 25-52, 2004.

FONTELES, José Osmar. Turismo e impactos socioambientais. São Paulo: Aleph, 2004.

GUTIÉRREZ, Maria de los Milagros. El Modelo Todo Incluído en Cuba: Evolución y Perspectiva. Revista Economia y Desarrollo. n. 1, v. 130, p. 116-137, ene/jun. 2002.

KRIPPENDORF, Jost. Sociologia do Turismo: para uma nova compreensão do lazer e das viagens. 3. ed. São Paulo: Aleph, 2003.

MARX, Karl. O capital: crítica da economia política. 22. ed. Rio de Janeiro: Civilização Brasileira, 2004.

MÉSZÁROS, István. A teoria da alienação em Marx. São Paulo: Boitempo, 2006.

MORAES, Antonio Carlos Robert. Contribuições para a gestão da zona costeira do Brasil: elementos para uma geografia do litoral brasileiro. São Paulo: Hucitec, 1999.

. Ideologias geográficas: espaço, cultura e política no Brasil. 5. ed. São Paulo: Annablume, 2005.
OURIQUES, Helton. A produção do turismo: fetichismo e dependência. Campinas: Alínea, 2005.

PEARCE, Douglas. Geografia do turismo: fluxos e regiões no mercado de viagens. São Paulo: Aleph, 2003.

SCHUMACHER, Ernst. O negócio é ser pequeno: um estudo de economia que leva em conta as pessoas. 2. ed. Rio de Janeiro: Zahar Editores, 1983.

SALVATI, Sergio (Org.). Turismo responsável: manual para políticas públicas. Brasília: WWF Brasil/BID, 2004.

SANTOS, Milton. Espaço e método. São Paulo: Nobel, 1985.

. A natureza do espaço: técnica e tempo, razão e emoção. 4. ed. São Paulo: Edusp, 2004a.

SANTOS, Milton. Pensando o espaço do homem. 5. ed, São Paulo: Edusp, 2004b.

SELVA, Vanice. et al. Ecos do turismo na comunidade de Avero-Mar (Sirinhaém-PE): uma reflexão partilhada para o desenvolvimento local sustentável. Diagnóstico participativo da comunidade de Aver-o-Mar sobre o desenvolvimento do turismo na Praia de Gamela (área de proteção ambiental de Guadalupe). Recife: Mestrado em Geografia/Mestrado em Gestão e Políticas Ambientais, 2006. Relatório Técnico Universidade Federal de Pernambuco.

TORRES, Rebecca. Cancun's tourism development from a fordist spectrum of analysis. Tourist Studies. London, v. 2, n. 1, p. 87-116, 2002.

URRY, John. O olhar do turista: lazer e viagens nas sociedades contemporâneas. São Paulo: Studio Nobel, 1996. 